\title{
BEBAN FAMILY CAREGIVER DALAM MERAWAT PASIEN KANKER STADIUM LANJUT
}

\author{
Yulia Rizka ${ }^{1}$ Erwin $^{2}$, Yessi Hasneli ${ }^{3}$, Nila Putriana ${ }^{4}$ \\ ${ }^{1,2,3}$ Faculty of Nursing, University of Riau \\ ${ }^{4}$ Arifin Achmad General Hospital, Pekanbaru, Riau \\ Email : yuliarizkasofyan@gmail.com
}

\begin{abstract}
Abstrak
Family caregiver memberikan perawatan suportif bagi anggota keluarganya yang menderita kanker dan terlibat dalam banyak aspek perawatan. Tujuan dari penelitian ini adalah untuk mendeskripsikan beban family caregiver saat merawat pasien kanker stadium lanjut. Penelitian deskriptif dengan pendekatan crosssectional dan teknik purposive sampling, sehingga didapatkan 75 family caregiver sebagai sample. Data dikumpulkan dengan menggunakan instrumen yang telah valid, yaitu Caregiver Reaction Assessment (CRA) di Rumah Sakit Umum Daerah di Pekanbaru tahun 2019. Analisis univariat digunakan untuk menggambarkan beban family caregiver. Analisis univariat menunjukkan bahwa rata-rata usia family caregiver adalah 36 tahun, didominasi oleh perempuan (52\%). Sebagian besar family caregiver memiliki pengalaman sebelumnya dalam merawat orang sakit (60\%). Mayoritas family caregiver mendampingi pasien kanker selama $<12$ bulan $(56 \%)$. Rata-rata beban family caregiver selama merawat pasien kanker adalah 2,25 yang berarti mereka merasa sedikit terbebani. Identifikasi dini diperlukan untuk mencegah penurunan kualitas hidup family caregiver.
\end{abstract}

Kata kunci : Kanker stadium lanjut, beban, family caregiver

\begin{abstract}
Family caregiver provides supportive care for their family members who suffer from cancer and involve in many aspects of the disease care. The aim of this study is to describe of family caregivers burden while caring in advanced cancer patients. Descriptive study with a cross-sectional survey was performed and purposive sampling on 75 family caregiver. Data were collected by using validated instruments of Caregiver Reaction Assessment (CRA) questionnaire from the General Hospital in Pekanbaru in 2019. Univariate analysis used to describe of the burden of family caregivers. Univariate analysis shown that mean age of the family caregiver is 36 years old, dominated by women (52\%). Most family caregiver have previous experience in caring for the sick (60\%) and have taken to patients less than 12 months (56\%). The average family burden while caring for cancer patients is 2.25, which means that they feel a little burdened. Early identification is necessary to prevent a decline in the life quality of family caregivers.
\end{abstract}

Keywords : Advanced cancer, burden, family caregiver

\section{PENDAHULUAN}

Kanker merupakan penyebab kematian kedua di dunia, sekitar 8,8 juta orang meninggal akibat kanker pada tahun 2015 (World Health Organization, 2017). Berdasarkan data Riset Kesehatan Dasar (Riskesdas) tahun 2013, prevalensi kanker di Indonesia 1,4 per 1000 penduduk yang berarti sekitar 2 orang dari 1000 penduduk Indonesia menderita kanker.
Prevalensi kanker di Riau sekitar 0,7 per 1000 penduduk yang berarti sekitar 1 orang dari 1000 penduduk di Riau menderita kanker (Riskesdas, 2013).

Pasien kanker mengalami berbagai gejala yang disebabkan oleh penyakit kanker dan efek pengobatan. Keluarga merupakan caregiver terdekat pasien yang mengetahui gejala yang dialami oleh pasien karena 
Yulia Rizka, Erwin, Yessi Hasneli, Nila Putriana, Beban Family Caregiver Dalam Merawat Pasien Kanker Stadium Lanjut

perawatan anggota keluarga yang sakit merupakan bagian dari budaya Asia yang membuat keluarga secara inisiatif akan menerima tugas tersebut sebagai suatu kewajiban. Di Indonesia, hubungan kekeluargaan yang erat membuat family caregiver terlibat dalam perawatan pasien baik selama di rumah sakit maupun di rumah (Effendy et al., 2015). Keterlibatan keluarga dalam perawatan pasien meliputi activity daily living, masalah fisik, sosial, psikologi, otonomi, spiritual, dan keuangan (Rizka et al., 2021).

Keterlibatan family caregiver dalam perawatan pasien dipengaruhi oleh berbagai faktor, antara lain masalah keuangan motivasi dan kepercayaan dari keluarga untuk dapat memberikan perawatan terbaik untuk pasien, keterbatasan dalam memilih pelayanan keperawatan untuk pasien, dan tidak memiliki pilihan lain selain merawat sendiri keluarga yang sakit (Rochmawati et al, 2016; Kristanti et al., 2019). Keluarga terlibat di berbagai aspek perawatan pasien selama pasien menjalani perawatan di rumah sakit, antara lain membantu memenuhi kebutuhan sehari-hari pasien (ADL) dan personal hygiene, mempersiapkan makanan dan obat-obatan pasien, membantu mengatasi masalah fisik dan psikologis pasien, dan membantu dalam proses pengambilan keputusan terkait perawatan pasien (Effendy et al., 2015; Kristanti et al., 2019).
Family caregiver burden yang tinggi dapat dipengaruhi oleh status fungsional pasien (Rha e al., 2015; Grunfeld et al., 2004) Hasil penelitian sebelumnya menunjukkan bahwa beban family caregiver semakin berat dalam merawat pasien kanker apabila kondisi fungsional pasien mengalami penurunan. Pasien kanker yang mengalami penurunan fungsional akan bergantung pada family caregiver untuk aktifitas sehari-hari, sehingga mempengaruhi jadwal pekerjaan dan kondisi kesehatan family cergiver (Yoon, 2003). Beban family caregiver akan semakin berat ketika merawat pasien kanker yang menjalani hospitalisasi karena di Indonesia pasien ditemani hampir 24 jam oleh keluarga, sehingga berdampak terhadap aktivitas seharihari family caregiver (Sari et al., 2018; Effendy et al., 2015; Rha $e$ al., 2015). Durasi perawat yang lama pada pasien kanker akan berdampak terhadap finansial dan psikologis family caregiver akibat kurangnya dukungan dari lingkungan sekitar (Yoon, 2003). Selain itu, gejala-gejala yang dialami pasien kanker, seperti dispnea, kecemasan, dan depresi mempengaruhi beban family caregiver (Krug et al., 2016). Oleh sebab itu, penelitian ini bertujuan untuk mengetahui gambaran beban family caregiver saat merawat pasien kanker stadium lanjut.

\section{METODE PENELITIAN}

Penelitian ini merupakan penelitian deskriptif dengan pendekatan cross sectional, 
yaitu pengukuran hanya dilakukan satu kali dalam satu waktu. Teknik sampling berupa purposive sampling. Jumlah sampel pada penelitian ini adalah 75 family caregiver. Kriteria inklusi family caregiver pada penelitian ini adalah: 1) Family caregiver yang menemani pasien kanker minimal 3 hari; 2) Berusia lebih dari 18 tahun; 3) Memberikan bantuan perawatan kepada pasien sehari-hari; 4) Dapat diajak berkomunikasi; 5) Bersedia menjadi responden. Kriteria ekslusi family caregiver pada penelitian ini adalah seseorang yang menunggui pasien kanker tetapi bukan merupakan bagian dari keluarga pasien (pembantu atau tetangga).

Alat pengumpul data yang digunakan yaitu kuesioner Caregiver Reaction Assessment (CRA) untuk menilai beban keluarga. Kuesioner ini terdiri dari 24 item pernyataan dengan lima subskala, yaitu empat subskala menilai tentang aspek negatif pada caregiver dan satu subskala menilai tentang aspek positif pada caregiver. Masing-masing item memiliki pilihan jawaban dengan 5 poin skala Likert dari sangat tidak setuju sampai sangat setuju dengan rentang nilai dari 1 sampai 5. Penilaian pernyataan yang bersifat positif (favorable) sesuai dengan instrumen, sementara jika pernyataan bersifat negatif (unfavorable) maka penilaian berlaku sebaliknya. Skor yang lebih tinggi menunjukkan beban keluarga yang lebih besar baik di setiap subskala maupun total nilai keseluruhan (Given et al., 1992; Grov et al., 2006). Kuesioner CRA sudah dilakukan proses translasi oleh peneliti sebelumnya serta uji validitas dan reliabilitas dengan nilai Cronbach's alpha 0.761 (Sari et al., 2018).

Uji statistik univariat digunakan untuk mendapatkan gambaran karakteristik demografi family caregiver yang terdiri dari usia, jenis kelamin, pengalaman merawat pasien, durasi merawat pasien dan beban family caregiver dalam merawat pasien kanker.

Penelitian ini telah mendapatkan persetujuan dari Komite Etik Fakultas Keperawatan Universitas Riau. Seluruh responden pada penelitian ini telah menandatangani informed consent untuk berpartisipasi dalam penelitian.

\section{HASIL PENELITIAN}

Karakteristik responden berupa sosiodemografi yang terdiri dari usia, jenis kelamin, pengalaman merawat sebelumnya, lama merawat pasien dapat dilihat pada tabel 1.

\section{Tabel 1.}

Karakteristik sosiodemografi keluarga pasien kanker

\begin{tabular}{lccc}
\hline Karakteristik & $\begin{array}{c}\text { Frekuensi } \\
(\mathbf{f})\end{array}$ & $\begin{array}{c}\text { Persentase } \\
(\boldsymbol{\%})\end{array}$ & Mean \pm SD \\
Usia & & & $35,80 \pm 12,22$ \\
Pengalaman & & & - \\
merawat & 30 & 40,0 & \\
$\quad$ Belum pernah & 45 & 60,0 & \\
$\quad$ Sudah pernah & & & \\
Lama merawat & & 56 & \\
pasien & 42 & 44 & \\
$\quad<12$ bulan & 33 & & \\
$\quad$ 212 bulan & & 48,0 & \\
Jenis kelamin & 36 & 52,0 & \\
$\quad$ Laki-laki & 39 & &
\end{tabular}


Yulia Rizka, Erwin, Yessi Hasneli, Nila Putriana, Beban Family Caregiver Dalam Merawat Pasien Kanker Stadium Lanjut

Berdasarkan hasil penelitian, rata-rata usia family caregiver adalah 36 tahun, didominasi oleh family caregiver perempuan sebanyak 39 orang (52\%). Mayoritas family caregiver sudah memiliki pengalaman sebelumnya dalam merawat orang sakit sebanyak 45 orang (60\%). Mayoritas family caregiver telah merawat pasien kanker selama $<12$ bulan sebanyak 42 orang $(56 \%)$.

Gambaran beban family caregiver dalam merawat pasien kanker dapat dilihat pada tabel 2 .

Rata-rata beban family caregiver selama merawat pasien kanker adalah 2,25 yang berarti family caregiver merasa sedikit terbebani terhadap perawatan yang selama ini diberikan pada pasien kanker.

\section{Tabel 2.}

Gambaran beban family caregiver

\begin{tabular}{lcc}
\hline Karakteristik & Mean & SD \\
\hline Family caregiver & 2,25 & 0,39 \\
burden $^{a}$ & \\
${ }^{a}$ Diukur dengan menggunakan Caregiver Reaction \\
Assessment \\
(semakin tinggi skor, semakin besar beban keluarga)
\end{tabular}

\section{PEMBAHASAN}

\section{Karakteristik Sosiodemografi}

\section{a. Usia}

Usia family caregiver pada penelitian ini rata-rata pada kategori dewasa muda. Menurut penelitian sebelumnya (Koumoutzis et al., 2020) family caregiver pada kategori usia dewasa muda secara fisik memiliki status kesehatan yang lebih baik dibanding family caregiver usia paruh baya karena semakin bertambah usia maka status kesehatan mengalami penurunan dalam memberikan perawatan pada anggota keluarga yang sakit. Selain itu, family caregiver dengan usia dewasa muda memiliki beban perawatan dan ketegangan fisik yang lebih sedikit dibanding usia paruh baya (Koumoutzis et al., 2020). Hal ini dapat dipengaruhi oleh pengalaman family caregiver dalam memberikan pengasuhan/perawatan sebelumnya.

\section{b. Jenis Kelamin}

Wanita memiliki tanggung jawab yang besar di masyarakat dengan peran sebagai pengasuh di beberapa aspek kehidupan, seperti pasien, anak-anak, pekerjaan, rumah tangga, sosial, dan Pendidikan (Kilic \& Oz, 2019). Pengalaman sosial mulai dari masa kanakkanak hingga dewasa membuat wanita harus mengemban tanggung jawab sebagai family caregiver untuk anggota keluarga dengan berbagai kondisi medis. Kondisi ini membuat wanita harus mampu beradaptasi terhadap perannya sebagai family caregiver dalam setiap perawatan anggota keluarga yang sakit baik di rumah maupun di Rumah Sakit (Sharma et al., 2016).

\section{c. Pengalaman merawat}

Family caregiver bukan pemberi perawatan professional terlatih seperti dokter, perawat atau pengasuh informal 
lainnya. Family caregiver adalah pemberi perawatan yang berasal dari anggota keluarga atau teman, sehingga tidak memiliki pengalaman professional dalam merawat pasien kanker khususnya. Pengalaman ini biasanya dapat menimbulkan stress yang berdampak pada fisik dan psikologis family caregiver, sehingga dapat meningkatkan beban family caregiver (Bevans \& Sternberg, 2012).

\section{d. Lama merawat}

Durasi family caregiver dalam memberikan perawatan kepada pasien kanker dapat mempengaruhi beban. Penelitian (Werdani, 2020) menunjukkan bahwa, semakin lama family caregiver memberikan perawatan pada pasien kanker, maka akan semakin tinggi beban yang dialami sehingga dapat mempengaruhi status kesehatan family caregiver. Menurut (Wen et al., 2019) merawat pasien dengan penyakit terminal dapat meningkatkan tekanan psikologis dan menurunkan kualitas hidup yang menyebabkan peningkatan beban perawatan pada family caregiver. Selain itu, kelelahan, kesal terhadap situasi perawatan, perasaan tak berdaya dan putus asa terhadap proses perawatan yang berlangsung lama mempengaruhi beban family caregiver (Perry et al., 2010).

\section{Beban family caregiver}

Pemberian perawatan/pengasuhan pada keluarga mengakar kuat dalam ajaran agama dan budaya. Family caregiver meyakini bahwa merawat keluarga yang sakit memiliki nilai penting yang menjadi kemauan dan sumber kekuatan baik secara agama maupun budaya (Kristanti et al., 2019). Kondisi ini membuat family caregiver tetap bersedia merawat pasien kanker meskipun kesulitan karena rasa tanggung jawab dan pengalaman positif sebagai family caregiver (Liu, 2021).

\section{SIMPULAN}

Hasil penelitian ini menunjukkan bahwa family caregiver merasa sedikit terbebani terhadap perawatan yang selama ini diberikan pada pasien kanker.

\section{SARAN}

Hasil penelitian ini dapat menjadi dasar perawat dalam menentukan intervensi yang tepat untuk meningkatkan kualitas hidup pasien kanker dan keluarga.

\section{DAFTAR PUSTAKA}

Bevans, M. F., Sternberg, E.M., (2021). Caregiving Burden, Stress, and Health Effects Among Family Caregivers of Adult Cancer Patients. JAMA 25:307(4): 398-403. Doi: 10.1001/jama.2012.29

Effendy, C., Vernooij Dassen, M., Setiyarini, S., Kristanti, M. S., Tejawinata, S., Vissers, K., \& Engels, Y. (2015). Family caregivers' 
Yulia Rizka, Erwin, Yessi Hasneli, Nila Putriana, Beban Family Caregiver Dalam Merawat Pasien Kanker Stadium Lanjut

involvement in caring for a hospitalized patient with cancer and their quality of life in a country with strong family bonds. Psycho-Oncology 24(5), 585-591.

Given, C. W., Given, B., Stommel, M., Collins, C., King, S., \& Franklin, S. (1992). The caregiver reaction assessment (CRA) for caregivers to persons with chronic physical and mental impairments. Research in Nursing and Health, 15(4), 271-283

Grov, E. K., Fosså, S. D., Tønnessen, A., \& Dahl, A. A. (2006). The caregiver reaction assessment: psychometrics, and temporal stability in primary caregivers of Norwegian cancer patients in late palliative phase. Psycho-Oncology, 15(6), 517-527

Grunfeld, E., Coyle, D., Whelan, T., Clinch, J., Reyno, L.,Earle, C. C., Willan, A., Viola, R., Coristine, M., Janz, T., Glossop, R., (2004). Family caregiver burden: results of a longitudinal study of breast cancer patients and their principal caregivers. CMAJ 170 (12): 1795-801.

Kilic, S.T., Oz, F., (2019). Family Caregivers' Involvement in Caring with Cancer and their Quality of Life. Asian Pac J Cancer Prev 20(6): 1735-1741.

Koumoutzis, A., Cichy, K. E., DellmannJenkins, M., Blankemeyer, M., (2020). Age Differences and Similarities in Associated Stressors and Outcomes Among Young, Midlife, and Older Adult Family Caregivers. Int J Aging Hum Dev 92(4): 431-449.

Kristanti, M.S., Effendy, C., Utarini, A., Vernooij-Dassen, M., Engels, Y., (2019). The experience of family caregivers of patients with cancer in an Asian country: A grounded theory approach. Palliative Medicine 33(6): 676-684.

Krug, K., Miksch, A., Peters-Klimm, F., Engeser, P., Szecsenyl, J., (2016). Correlation between patient quality of life in palliative care and burden of their family caregivers: a prospective observational cohort study. $B M C$ Palliative Medicine 15(4): 1-8.

Liu, Z., (2021). Caregiving Burden among Family Caregivers of People with Advanced Cancer: A Literature Review. Nurs Health Care Int J 5(3): 1-8. Doi : 10.23880/nhij-16000240

Perry B, Dalton JE, Edwards M. (2010). Family caregivers' compassion fatigue in long-term facilities. Nurs Older People 22(4):26-31.

Rha, S. Y., Park, Y., Song, S. K., Lee, C. E., \& Lee, J. (2015). Caregiving burden and the quality of life family caregivers of cancer patients: the relationship and correlates. European Journal of Oncology Nursing 19(4), 376-382.

Rochmawati, E., Wiechula, R., Cameron, K., (2016). Current status of palliative care services in Indonesia: a literature review. Inter Nur Rev 63(2), 180-190.

Riset Kesehatan Dasar, (2013). Laporan Nasional 2013. [serial online] [cited 2015 April 03] [306 screens]. Available from: URL: http://www.depkes.go.id/resources/do wnload/general/Hasil\%20Riskesdas\% 202013.pdf

Rizka, Y., Effendy, C. Widyawati, (2021). Factors that influence cancer related fatigue in advanced cancer patients in Indonesia. International Journal of Pharmaceutical Research (Accepted for publication)

Sari, I.W.W., Warsini, S., Effendy, C., (2018). Burden Among Family Caregivers of Advanced Cancer Patients in Indonesia. Belitung Nursing Journal 4(3):295-303

Sharma, N., Chakrabarti, S., Grover, S., (2016). Gender differences in caregiving among family - caregivers of people with mental illnesses. World $J$ Psychiatry 6(1): 7-17. Doi: 10.5498/wjp.v6.i1.7

Wen F-H, Chen J-S, Chou W-C, Chang W-C, Shen WC, Hsieh C-H, et al. (2019). Family caregivers' subjective caregiving burden, quality of life, and 
depressive symptoms are associated with terminally ill cancer patients' distinct patterns of conjoint symptom distress and functional impairment in their last six months of life. J Pain Symptom Manage 57(1):64-72.

Werdani, Y.D.W., (2020). Length of caring duration increases burden and reduces health status of cancer patients' family caregivers in Surabaya, Indonesia. Public Health and Preventive Medicine Archive 8(1): 53-59.

World Health Organization., (2017). Cancer. Available from:

http://www.who.int/mediacentre/facts heets/fs297/en/

Yoon, H., (2003). Factors associated with family caregivers' burden and depression in Korea. Int J Aging Hum Dev 57(4): 291-311. Doi : 10.2190/YM2A-X9E1-YP2P-VFPL 